\title{
Impact of WHO guidelines on trends in HIV testing and ART initiation among children living with HIV in Zambia
}

\author{
Tendai Munthali ${ }^{1,2^{*}+}$, Charles Michelo ${ }^{1 \dagger}$, Paul Mee $^{3 \dagger}$, Crispin Moyo $^{5}$, Andrew Kashoka ${ }^{2}$, Liswaniso Liswaniso ${ }^{2}$, \\ Innocent Chiboma ${ }^{2}$ and Jim Todd ${ }^{4 \dagger}$
}

\begin{abstract}
Background: About 13 years since the introduction of antiretroviral therapy (ART) for children living with HIV (CLHIV) in Zambia, HIV/AIDS testing and treatment guidelines for children have evolved over the years with limited documentation of long-term trends in the numbers testing HIV positive and initiating ART. We examined trends in HIV testing and ART initiation in Zambia.

Methods: We conducted a retrospective cohort study using routinely collected patient level data from 496 health facilities across Zambia. We used Poisson regression to derive incident rate ratios and 95\% confidence intervals (95\% Cl) for background characteristics and used a Cuzick non-parametric test for trends to test the 13-year trends. Median time from testing to ART initiation in days and incidence rates were derived using life tables in survival analysis. We used multi-level random effects Poisson regression model to determine variations in time from HIV testing to ART initiation by facility.
\end{abstract}

Results: Overall, the cumulative proportion of the children who tested positive and initiated antiretroviral therapy (ART for HIV) from 2004 to 2017 was 69\% ( $n=99$ 592). During the period under review proportions of ART initiation increased from 52\% in 2004-2006 to 97\% in 2016-2017 ( $<<0.001)$ and time from testing to ART initiation reduced from a median of 17 days IQR (1-161) in 2004 to one day IQR (1-14), P<0.001 in 2016-2017. CLHIV were 15 times more likely to be initiated on ART in 2016-17 compared to period 2004-6 (IRR $=15.2,95 \% \mathrm{Cl} 14.7-15.7)$. Time to ART initiation increased with age and was higher in rural health facilities compared to urban facilities. About $11 \%$ of the variability in time to ART initiation in children could be attributed to differences between facilities.

Conclusions: The substantial increase in ART initiation and reduction in time to ART initiation among CLHIV identified in this study, reflects improvements in the paediatric HIV programme in Zambia in relation to health care delivery and adherence to national testing and treatment guidelines that were adapted from WHO guidelines. However, age-related differentials in rates of ART initiation suggests that urgent interventions are needed to sustain and further improve programme performance.

Keywords: Childhood HIV, HIV testing, ART initiation, HIV treatment, HIV trends in Zambia

\footnotetext{
*Correspondence: munthalitendai@gmail.com

${ }^{\dagger}$ Tendai Munthali, Charles Michelo, Paul Mee and Jim Todd have contributed equally to the work

${ }^{1}$ School of Public Health, University of Zambia, Lusaka, Zambia

Full list of author information is available at the end of the article
}

\section{Background}

Globally, there are about 37.9 million people living with HIV with about 24.5 million receiving antiretroviral therapy (ART) [1]. Among these, approximately 1.7 million are children under the age of 15 years, with only $54 \%$ of them receiving ART [1]. In Zambia there are 62, 000

c) The Author(s) 2020. This article is licensed under a Creative Commons Attribution 4.0 International License, which permits use, sharing, adaptation, distribution and reproduction in any medium or format, as long as you give appropriate credit to the original author(s) and the source, provide a link to the Creative Commons licence, and indicate if changes were made. The images or other third party material in this article are included in the article's Creative Commons licence, unless indicated otherwise in a credit line to the material. If material is not included in the article's Creative Commons licence and your intended use is not permitted by statutory regulation or exceeds the permitted use, you will need to obtain permission directly from the copyright holder. To view a copy of this licence, visit http://creativeco mmons.org/licenses/by/4.0/. The Creative Commons Public Domain Dedication waiver (http://creativecommons.org/publicdomain/ zero/1.0/) applies to the data made available in this article, unless otherwise stated in a credit line to the data. 
children living with HIV (CLHIV) with 79\% on ART and 3000 of them die from AIDS related illnesses annually [1, 2]. ART was first made available free of charge in Zambia in 2005 [3, 4] and since then treatment of children on ART has been based on the World Health Organization (WHO) treatment guidelines that are adapted for use in country. In 2006 WHO recommended initiating children on ART based on clinical staging (3/4) or CD4+ T cell counts $(<250$ cells $/ \mu \mathrm{l} / \mathrm{CD} 4 \%<25 \%)$ [5]. The guidelines were then revised in 2008 recommending ART for all children less than 12 months regardless of CD4 count [6]. By 2010, WHO further revised the guidelines recommending immediate initiation on ART for all infants and children less than 2 years regardless of immunologic or clinical thresholds and for all children aged $2-5$ years with clinical stages $3 / 4$ or CD $4<750$ cells $/ \mu \mathrm{l}$ or $25 \%$ [6]. In 2013, the WHO guidelines were revised to recommend immediate treatment for all children $<5$ years old [7]. The current guidelines (2016) now recommend immediate initiation on ART for all HIV infected children regardless of age under the test and treat guidelines [8].

These changes in the guidelines have resulted in improvements in HIV testing and ART initiation among children [9-12]. However children still fall through the gaps and present for testing and ART initiation at older ages and in late HIV stages [11]. A study of 565 children initiating ART from 2004 to 2008 at one urban and two rural clinics in Zambia showed that about $50 \%$ of children started treatment between the ages 5 to 10 years [12]. Similar trends were seen in a study in Tanzania from 2004 to 2011 among children in 26 clinics where children were initiated on ART at a median age of 5.2 years [13].

In 2018, 13 years later after the introduction of ART in Zambia there are improved HIV testing services and better ART availability for CLHIV [14-16]. Studies conducted in sub-populations of children in Zambia have shown changes in the baseline characteristics of children testing HIV positive and initiating ART [14, 15]. However, little is known about long-term and country-wide characteristics of children diagnosed with HIV and initiating ART in Zambia. This paper uses national routine patient data to describe the baseline characteristics of children in Zambia from HIV testing to ART initiation and how these characteristics have changed over a 13-year period.

\section{Methods}

\section{Study population}

This study was a retrospective cohort study of children with records in the Zambian SmartCare data system. SmartCare is an electronic patient monitoring system which is used in many health facilities across all districts in Zambia [17-19]. Each patient is given a unique identification number at the first contact with the clinic and then subsequent records are entered into the database at each visit to health facility. The patient's records are entered in SmartCare either electronically during the visit or after the patient has been attended to by entering the data from a paper-based patient file. SmartCare data is collected for routine patient monitoring but is prone to missing data in both the electronic database and in paper-based format. A total of 99,592, children less than 15 years of age at the time of HIV diagnosis with records in SmartCare regardless of missing data during the period under review were included in the analysis.

\section{Clinical procedures}

In the Zambian health care system, all children with a positive serological test for HIV are eligible for enrolment into care. At the initial evaluation visit, a record is taken of medical history, physical examination, anthropometric measurements, socio demographic information and determination of WHO disease stage. All CLHIV should receive HIV care according to national testing and treatment guidelines which includes, the measurement of CD4+ T-cell counts or percentages, haemoglobin levels (HB), renal and liver function tests and HIV viral loads prior to starting ART. Treatment eligibility is determined based on the WHO and/or national treatment guidelines in effect at the time of HIV testing. Eligible CLHIV are treated with a first-line regimen and asked to return for clinical evaluation at week 2 , week 4 and then every 3 months for stable children [20,21].

\section{Data extraction and analysis}

The data for this analysis were extracted from SmartCare and saved in Excel (Microsoft Corp, Seattle) format for cleaning. The data was then exported to Stata version 13 (Stata Corp, College Station, Texas) for analysis. Two date variables were used from the dataset, the date of the first HIV positive test result (HIV diagnosis) and the date initiated on ART. These dates were used to derive the year of HIV test, the year of ART initiation, and the time between HIV diagnosis and ART initiation. The time variables were grouped into the following year bands: 2004-2006, 2007-2009, 2010-2012, 20132015 and 2016-2017, which roughly correspond to the years when Zambia implemented the WHO guidelines for ART in children. The ages of the children were categorised into four categories: those less than 18 months, 18-59 months, 5-9 years and 10-15 years. In addition health facilities were categorised into Hospitals, health centres, hospices and health posts as classified by the Zambia Health facility listing [18]. 


\section{Statistical methods}

Duplicate results were removed in Stata using the child's ID, date of birth and relevant variables such as laboratory results, pharmacy visit and HIV test dates. For continuous data, a test for normality was performed and data that were not normally distributed were described using the median and inter quartile ranges (IQR), while normally distributed data were described using means and standard deviations. The two baseline characteristics: tested for HIV and initiated on ART were used as dependent variables. Frequencies and percentages were used for categorical data and the Cuzick non-parametric test for trends (which is a Wilcoxon-type test for ordinal data) was used to show the changes in proportions testing HIV positive across time for the different levels of the explanatory variables. Models for trend testing were selected based on type of independent variable. All variables that were tested for trends were ordinal and had two or more categories.

We declared the data as survival data using the time from HIV testing to initiation on ART using parametric survival analysis to estimate the rate of ART initiation. Dates when the child was enrolled into HIV care, the date of death for those that died or whether they were put on ART or not were used to censor the data in survival analysis. Incident rate ratios were derived using Poisson regression and a Wald test was used to assess significance. Mixed multi-level random effects regression modelling was used to show variability of time from HIV testing to ART initiation among the children attributable to type of facility used at ART initiation. Wald tests were used to compare goodness of fit for crude and adjusted models.

Cumulative aggregate numbers of children initiating ART from the UNICEF's Stocktaking reports and the UNAIDS country reports published during the period under review were also compiled and compared to SmartCare numbers to validate trends in our analysis.

\section{Results \\ Participants}

A total of 99,592 children were recorded as having a positive HIV test result from 496 health facilities across Zambia during the period under review. Of these children $52 \%(52,109)$ were female and $48 \%(47,483)$ were males. In this analysis a total sampling of all children in 496 health facilities and 71 districts from all ten provinces of the country with relevant records in SmartCare was conducted. Out of the 99,592 children recorded as having an HIV positive diagnosis between 2004 and 2017, $69 \%(68,630)$ had records showing they started antiretroviral therapy (ART). Overall mortality for the period under review was 6\% $(5817 / 99,592)$. Mortality in children who tested positive, was $7 \%$ before ART initiation $(2167 / 31,097)$ and $5 \%(3431 / 68,630)$ in children after initiating ART. In addition, a total of $31 \%(31,097)$ of children that tested HIV positive had no record in SmartCare of ART initiation. For the children with records of ART initiation, after ART initiation, additional data on weight, height and clinical data are not well recorded or were missing in most cases, see Fig. 1.

The median age for HIV testing was 2 years with an interquartile range of (IQR) 1 to 4 years. Most of the records were from Lusaka (25\%), Southern (17\%), Copperbelt (21\%) and Eastern provinces (10\%). Western, Northern, Muchinga, Central, North-western and Luapula provinces each contributed less than $10 \%$ of the records, see Table 1.

\section{HIV testing over time}

The percentage of children testing HIV positive in the age groups from birth to 17 months and from 18 months to 4 years was highest in the period between 2007 and 2009 at $30 \%$ but declined steadily over the years. In contrast among the 10 to 15 age group, HIV testing was lowest in between 2007-2009 at 17\% and increased over the years to $26 \%$ by the end of 2017 . Median age at testing has remained high over the years with the lowest age at testing being 3 years IQR (1-8) in 2007-2009, see Table 2. Of those who tested HIV positive, most children (55\%) were tested in hospitals in 2004-2006 however, this trend reduced to $37 \%$ between 2016 and 2017 with increasing testing in the other facilities ( $\mathrm{p}$-value $<0.001$ ).

\section{Estimation of time-to-ART initiation over time}

The median time from testing to initiating ART reduced from 17 days IQR (1-161) in 2004 to 2006 to one day IQR (1-14) in the period 2016-2017. Time to ART initiation increased with increasing age of the children with children aged from 5 to 9 years taking the longest time to be initiated on ART (14 days IQR (1-112) during the same period. Hospices had the longest time to ART initiation at 28 days IQR $(1-357)$ while health posts had the lowest time to initiation at 1 -day IQR (1-37) see Table 3.

Children were 15.2 times more likely to be initiated on ART in 2016-2017 compared to the period 2004-2006 $(1 \mathrm{RR}=15.2$, 95\% CI 14.7-15.7, $\mathrm{p}$-value <0.001) after adjusting for other variables (sex, province, age at HIV test, type of health care facility used). In estimating rates of ART initiation, the overall ART initiation rate was estimated at 0.14 per month or 1.68 per year, while the rate for ART initiation increased over the reporting period from 10 per 100-person months in 2004-2006 to 106 per 100-person months in 2016-2017. Since 2014 almost all children who tested positive for HIV have initiated ART, 


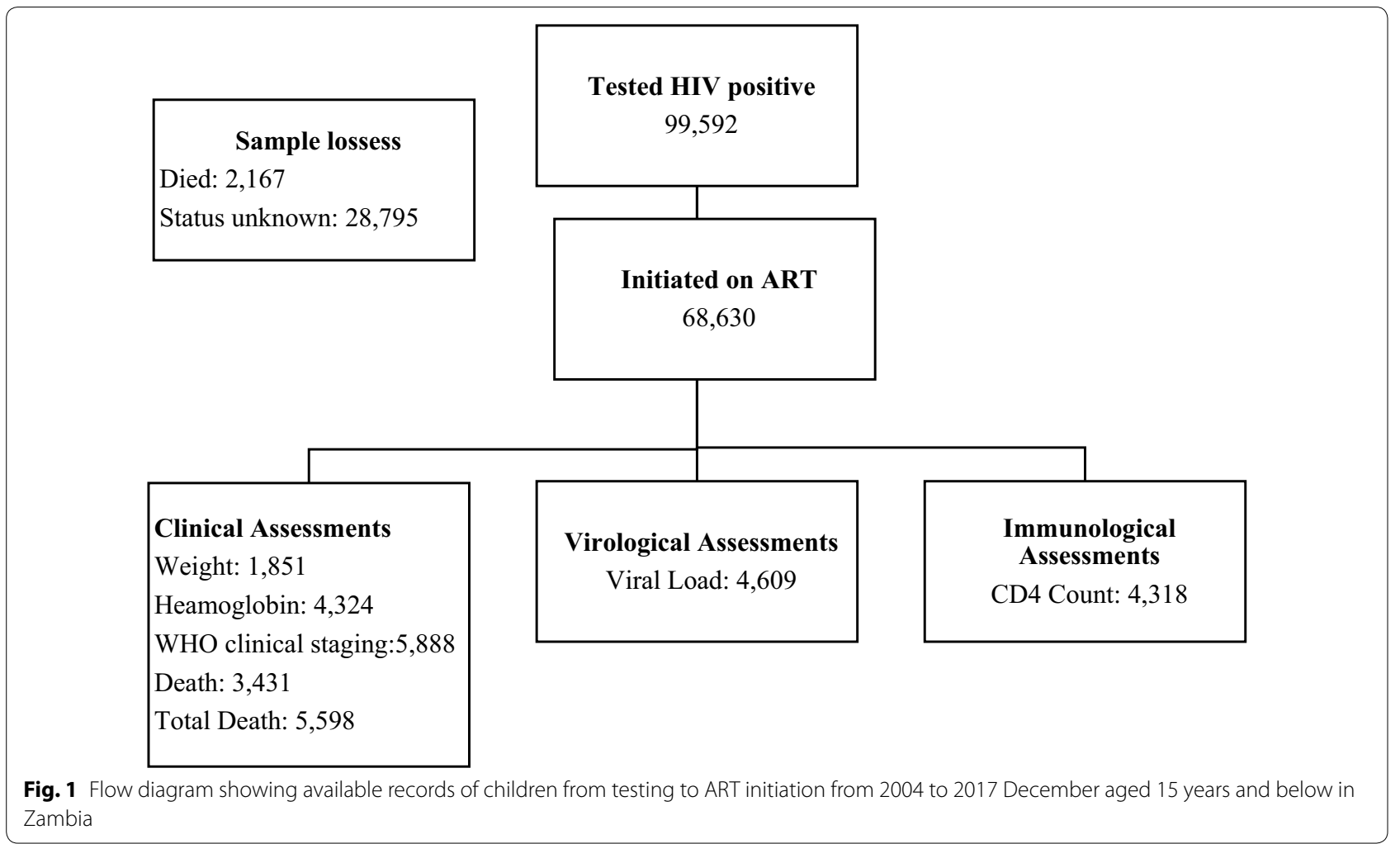

Table 1 Baseline characteristics of children diagnosed with HIV from 2004 to 2017 in Zambia

\begin{tabular}{llr}
\hline Characteristic & Population \\
\cline { 2 - 3 } & N & $\%$ \\
\hline Sex & & \\
Female & 52,209 & 52 \\
Male & 47,483 & 48 \\
Age of the children & & \\
Age at HIV test Median (IQR) & $2(1-4)$ & \\
Province & & 25 \\
Lusaka & 25,343 & 21 \\
Copperbelt & 20,701 & 17 \\
Southern & 16,498 & 10 \\
Eastern & 10,312 & 7 \\
Central & 7097 & 4 \\
North-western & 3664 & 3 \\
Northern & 3160 & 3 \\
Luapula & 3458 & 7 \\
Western & 7081 & 2 \\
Muchinga & 2277 & 100 \\
Total & 99,592 & \\
\hline
\end{tabular}

and the median time for ART initiation has dropped from 1 month in 2014 to 1 day in 2017 (Fig. 2). Furthermore, the ART initiation rates reduced with increasing age groups from 16 per 100-person months in the youngest age group, to 14 per 100 -person months among children aged 10 to 15 years during the same period.

\section{Characteristics of children at ART initiation}

Overall, the percentage of children who tested HIV positive who were initiated on ART increased over the years to $97 \%$ as of December 2017 from 52\% in 2004-2006 (Table 2). Children from birth to 17 months recorded the lowest percentages of ART initiation among all the age groups with percentages under $20 \%$ over the period under review. In contrast, percentages of children initiating ART among the 10 to 15 age group were highest at above $25 \%$ with the highest percentage recorded between 2016 and 2017 ( $\mathrm{p}$-value $<0.001 \mathrm{z}=8.93$ ). The proportion of children initiating ART in urban districts continued to be high over the period under review with initiations in urban districts maintaining more than $85 \%$ ART initiation rates, see Table 4.

\section{Comparison of national estimates of children initiated into care with UNICEF and UNAIDS estimates}

Cumulative numbers of all children initiating ART in SmartCare over the period under review and aggregate 
Table 2 Baseline characteristics of children at HIV positive diagnosis in Zambia from 2004 to 2017

\begin{tabular}{|c|c|c|c|c|c|c|}
\hline Characteristic & $\begin{array}{l}2004 / 2006 \\
n=12,087\end{array}$ & $\begin{array}{l}2007 / 2009 \\
n=30,848\end{array}$ & $\begin{array}{l}2010 / 2012 \\
n=2917\end{array}$ & $\begin{array}{l}2013 / 2015 \\
n=2028\end{array}$ & $\begin{array}{l}2016 / 2017 \\
n=7212\end{array}$ & P-value* \\
\hline Age n (\%) & & & & & & $<0.001$ \\
\hline Birth-17 months & $1860(16)$ & $8948(30)$ & $8140(28)$ & $4499(23)$ & $1546(22)$ & \\
\hline 18 months -4 years & $3391(29)$ & $8936(30)$ & $7976(28)$ & $5431(28)$ & $1872(27)$ & \\
\hline $5-9$ years & $3740(32)$ & 7074 (23) & $6989(24)$ & $5183(26)$ & $1798(26)$ & \\
\hline 10-15 years & $2788(24)$ & $5227(17)$ & $5483(19)$ & $4535(23)$ & $1823(26)$ & \\
\hline Median age (IQR) & $6(2-10)$ & $3(1-8)$ & $4(1-9)$ & $5(2-10)$ & $5(2-11)$ & \\
\hline $\operatorname{Sexn}(\%)$ & & & & & & $<0.001$ \\
\hline Male & $5868(49)$ & $15,018(49)$ & $13,740(47)$ & $9446(47)$ & $3411(47)$ & \\
\hline Female & $6219(51)$ & $15,830(51)$ & $15,457(53)$ & $10,802(53)$ & $3801(53)$ & \\
\hline Place of testing n (\%) & & & & & & $<0.001$ \\
\hline Hospital & $6682(55)$ & $16,990(55)$ & $13,383(46)$ & 7759 (38) & $2658(37)$ & \\
\hline Health Centre & $5393(45)$ & $13721(44)$ & $15477(53)$ & $12,149(60)$ & $4217(58)$ & \\
\hline District type n (\%) & & & & & & $<0.001$ \\
\hline Rural & $811(7)$ & $3791(12)$ & $4538(16)$ & $3395(17)$ & $836(12)$ & \\
\hline Urban & $11,276(93)$ & $27,057(88)$ & $24,659(83)$ & $16,852(83)$ & $6376(88)$ & \\
\hline ART initiation status n (\%) & & & & & & $<0.001$ \\
\hline Initiated on ART & $6217(52 \%)$ & $16,940(55 \%)$ & $19,780(68 \%)$ & 18,768 (93\%) & 6925 (97\%) & \\
\hline
\end{tabular}

$I Q R$ interquartile range

*Tested using cuzick non-parametric test for trends

data reported in stocktaking reports published by UNICEF [22-26] and UNAIDS global reports and country data factsheets [27-31] show similar upward trends with minor differences among the data sources see Fig. 3. Our data shows slightly higher trends from 2009 to 2013 and from 2014 to 2017 despite the data coming from a percentage of health facilities in the country.

\section{Post regression estimates of time to ART initiation} from multilevel regression clustering at facility level The mixed random effects model showed significant variability in time to ART initiation by age at ART initiation and district type depending on the health facility used at ART initiation. Generally, time to ART initiation increased with an increase in age while it reduced by $25 \%$ $(I R R=0.117,95 \%$ CI $0.099-0.138)$ in urban areas compared to rural areas see Table 5 .

\section{Discussion}

This study describes the baseline characteristics of close to 100,000 children who were diagnosed with HIV over a 13-year period in facilities using SmartCare across Zambia. Our observations suggest that there was a substantial improvement in childhood HIV health care delivery and service uptake over years analysed. This is evidenced by improvements in specific parameters such time to ART initiation which reduced drastically during the same period. The data also shows the impact of the
WHO guidelines over time with almost $100 \%$ of children diagnosed with HIV initiating ART since 2014. The 2013 and 2016 WHO guidelines which recommended immediate ART initiation for children have been instrumental in bringing down the delay in initiating ART, with most children now starting ART on the same day they receive their HIV diagnosis.

Despite these overall improvements there were lower rates of HIV testing and longer times to ART initiation for particular groups. Those aged 5-9 had the lowest rates of HIV testing and those aged 10-15 took longest to initiate ART treatment. Estimations of the numbers of children initiated on ART in our study were also found to be higher than estimates reported in UNAIDS and UNICEF documents. Our data shows that $97 \%$ of children diagnosed with HIV in 2016-2017 were initiated on ART which is higher than the UNAIDS estimation for Zambia that showed that $52 \%$ of children diagnosed with HIV were initiated on ART in 2017 [32]. The reasons for these differences were not the primary focus of this paper. However, disparity in percentages could be attributed to the differences in the reporting period and facility coverage. Our higher percentage is in line with reports from the Ministry of Health that showed a $65 \%$ increase in percentages of people initiating ART between 2016 and 2017 after the implementation of the test and treat strategy [33]. It is possible that our estimates have been affected by bias common when using routinely collected 
Table 3 Incidence rate ratios time from testing to ART and incident rates of children living with HIV in Zambia from 2004 to 2017

\begin{tabular}{|c|c|c|c|c|c|c|}
\hline Characteristic & $\begin{array}{l}\text { Number } \\
\text { initiating ART }\end{array}$ & $\begin{array}{l}\text { Median time from Test } \\
\text { to ART in days (IQR) }\end{array}$ & $\begin{array}{l}\text { Rates of ART } \\
\text { initiation } 100 \\
\text { per month }\end{array}$ & $\begin{array}{l}\text { Person time } \\
\text { in years }\end{array}$ & $\begin{array}{l}\text { Unadjusted test } \\
\text { to ART IRR }(\mathrm{CI})^{*}\end{array}$ & $\begin{array}{l}\text { Adjusted } \\
\text { from test to ART } \\
\text { IRR (CI)* }\end{array}$ \\
\hline \multicolumn{7}{|l|}{ Sex } \\
\hline Male & 33,211 & $10(1-77)$ & 14 & 18,909 & 1 & 1 \\
\hline Female & 35,419 & $8(1-77)$ & 13.6 & 20,943 & $0.95(0.93-0.96)$ & $0.94(0.93-0.95)$ \\
\hline \multicolumn{7}{|l|}{ Years } \\
\hline 2004-2006 & 6217 & $17(1-161)$ & 7 & 9052 & 1 & 1 \\
\hline 2007-2009 & 16,940 & $11(1-111)$ & 10 & 14,972 & $1.36(1.32-1.39)$ & $1.34(1.31-1.38)$ \\
\hline 2010-2012 & 19,780 & $10(1-90)$ & 15 & 10,823 & $1.98(1.92-2.02)$ & $2.02(1.96-2.07)$ \\
\hline 2013-2015 & 18,768 & $9(1-50)$ & 33 & 3777 & $4.55(4.43-4.67)$ & $4.62(4.50-4.74)$ \\
\hline $2016-2017$ & 6925 & $1(1-14)$ & 106 & 421 & $14.5(13.9-14.9)$ & $15.2(14.7-15.7)$ \\
\hline \multicolumn{7}{|l|}{ Age group at test } \\
\hline Birth to 17 months & 12,141 & $1(1-55)$ & 16 & 6278 & 1 & 1 \\
\hline 18 months to 4 years & 18,953 & $8(1-73)$ & 14 & 10,860 & $0.91(0.88-0.92)$ & $0.92(0.90-0.94)$ \\
\hline $5-9$ years & 18,476 & $14(1-112)$ & 12 & 12,730 & $0.76(0.74-0.77)$ & $0.78(0.76-0.80)$ \\
\hline $10-15$ years & 17,215 & $13(1-77)$ & 14 & 9898 & $0.86(0.84-0.87)$ & $0.86(0.84-0.88)$ \\
\hline \multicolumn{7}{|l|}{ Health facility type } \\
\hline Hospital & 31,776 & $7(1-87)$ & 12 & 20,878 & 1 & 1 \\
\hline Health centre & 36,177 & $13(1-69)$ & 16 & 18,352 & $1.26(1-1.27)$ & $0.99(0.97-1.01)$ \\
\hline Hospice & 473 & $28(1-357)$ & 10 & 502 & $0.64(0.58-0.70)$ & $0.42(0.38-0.46)$ \\
\hline Health post & 133 & $1(1-37)$ & 14 & 118 & $1.14(0.99-1.31)$ & $0.69(0.60-0.80)$ \\
\hline \multicolumn{7}{|l|}{ Province } \\
\hline Central & 5174 & $1(1-42)$ & 21 & 1977 & 1 & 1 \\
\hline Luapula & 2677 & $1(1-13)$ & 24 & 880 & $1.22(1.16-1.27)$ & $1.06(1.01-1.11)$ \\
\hline Copperbelt & 15,423 & $1(1-46)$ & 14 & 8865 & $0.67(0.65-0.70)$ & $0.59(0.57-0.61)$ \\
\hline Eastern & 6758 & $14(1-115)$ & 11 & 4734 & $0.55(0.53-0.57)$ & $0.45(0.44-0.47)$ \\
\hline Lusaka & 17,886 & $19(1-84)$ & 12 & 11,114 & $0.62(0.60-0.63)$ & $0.62(0.61-0.64)$ \\
\hline Muchinga & 1340 & $1(1-18)$ & 18 & 599 & $0.89(0.84-0.94)$ & $0.80(0.76-0.85)$ \\
\hline North-western & 2599 & $3(1-58)$ & 15 & 1354 & $0.73(0.69-0.76)$ & $0.61(0.58-0.64)$ \\
\hline Northern & 2681 & $1(1-17)$ & 19 & 1129 & $0.93(0.89-0.97)$ & $0.69(0.66-0.72)$ \\
\hline Southern & 9424 & $18(1-136)$ & 11 & 6684 & $0.57(0.55-0.58)$ & $0.54(0.52-0.56)$ \\
\hline Western & 4668 & $16(1-91)$ & 14 & 2513 & $0.72(0.69-0.74)$ & $0.57(0.54-0.59)$ \\
\hline
\end{tabular}

IQR Interquartile range, $\mathrm{Cl}$ Confidence interval

*Tested using Poisson

data such as missing and incomplete records, as shown in the drop in the number children that were diagnosed with HIV from a peak of 31,602 between 2007 and 2009 to only 7270 in 2016/17. This bias included loss in sample size leading to only complete case analysis and possibly under or over estimation of estimates [34]. We propose that this could have been due to effective PMTCT programs that led to $96 \%$ of pregnant women living with HIV receiving ART and a more than $50 \%$ reduction in the number of HIV positive children born from HIV positive women between 2011 and 2012 [35].

There were also challenges in ART initiation when disaggregated by age group with time to ART initiation increasing with increasing age. In addition, $11 \%$ variability in time taken to ART initiation in factors affecting children at ART initiation could be attributed to type of facility used at ART initiation. Our data showed that children aged 5 to 9 years had the longest time to ART initiation and were less likely to be initiated on ART compared to children from birth to 17 months. This could be because until 2016, children above 5 years could only be initiated on ART once their CD4 count was below $350 \mathrm{mmol} / \mathrm{l}$ thereby increasing time to ART initiation. Another reason for the delay could be some AIDS defining conditions like TB that have overlapping symptoms and require initiation of ART after treatment of 
Proportion of CLHIV initiated on ART, Time on ART initiation VS years when WHO guidelines were published over the years 2004-2017

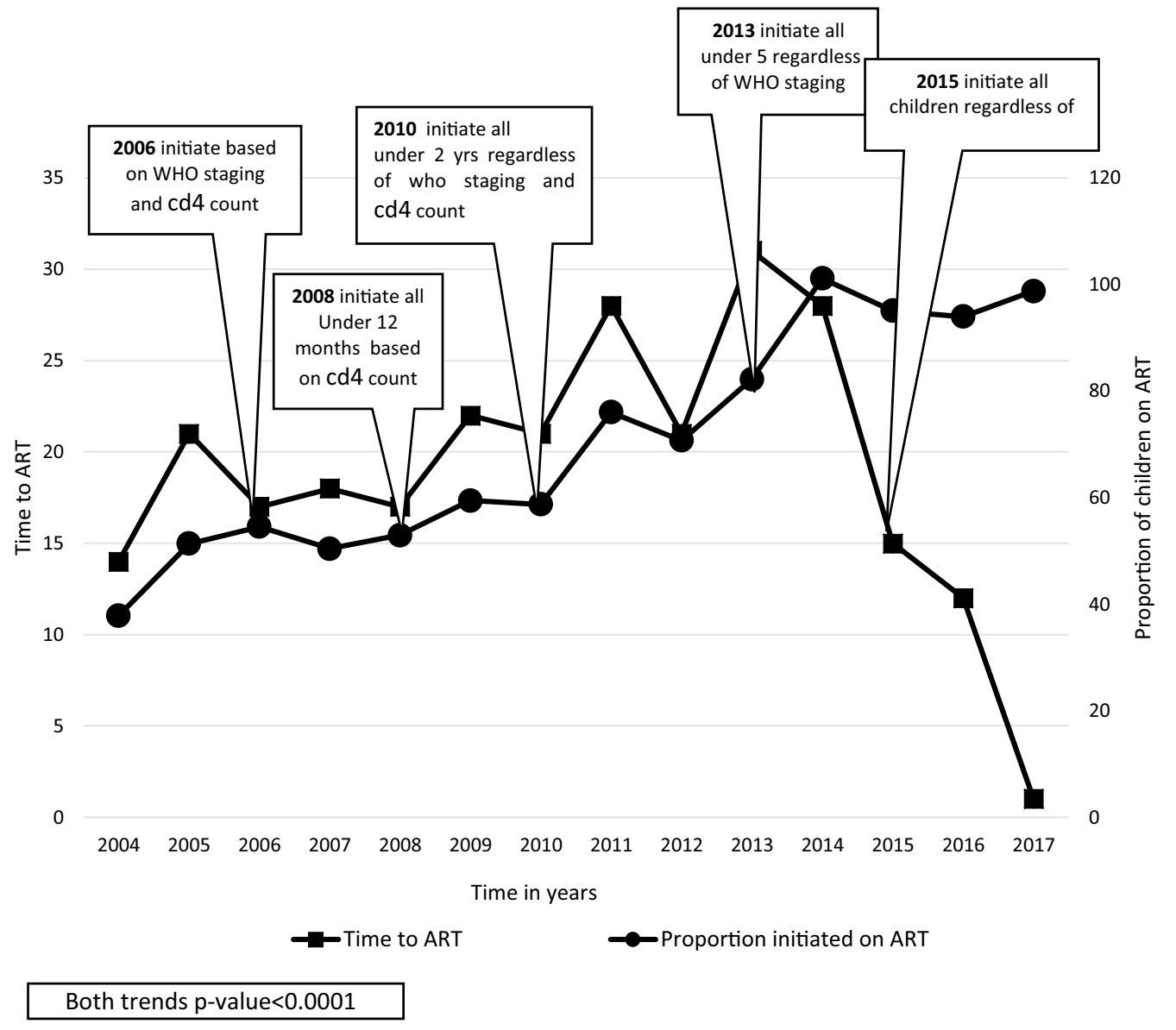

Fig. 2 Graph showing how median time to ART and proportions of children initiated on ART have changed with changing WHO guidelines over the years (2004-2017)

the condition is tolerated [36-39]. In addition, children above 5 have less contact with the health facilities after completion of the Mother and child health $(\mathrm{MCH})$ clinics immunization and growth monitoring schedule. Therefore, diagnosis for this age group is more likely after presenting with acute illness at health facilities [39]. Another area with challenges is the testing related dynamics where children aged 10 to 15 years had the lowest rates of HIV testing. This could be because until recently long-term survival of children not on ART following MTCT were thought to be uncommon and so testing strategies for this age group were not emphasized or were less robust $[10,39]$. Most children in our study were tested in hospitals in 2004-2006. However, this trend reduced between 2015 and 2017 with increasing testing in the other facilities types such as hospice and health posts showing the need for increased EID services at all health facility types [40]. We also found that more female children were tested over the study period. Reasons or this are beyond the scope of this study. However, sex related differentials among children testing for HIV have been reported in earlier studies in Zambia which showed more males testing for HIV among hospitalised children [10].

\section{Strengths and limitations}

To our knowledge, this paper is the first to show long term changes in the characteristics of HIV infected children from facilities across Zambia using routinely collected SmartCare data. The main strength of this study is the large sample size and the long follow up period which makes our findings generalizable to the whole population. In addition, we analysed data from public, private, military and faith-based health facilities that utilize SmartCare at different levels of the health care delivery system. Our analysis was merely descriptive which made it difficult to attribute causality and a more robust 
Table 4 Baseline characteristics of children ART initiation in Zambia from 2004 to 2017

\begin{tabular}{|c|c|c|c|c|c|c|}
\hline Characteristic & $\begin{array}{l}2004 / 2006 \\
n=6217\end{array}$ & $\begin{array}{l}2007 / 2009 \\
n=16,940\end{array}$ & $\begin{array}{l}2010 / 2012 \\
n=19,780\end{array}$ & $\begin{array}{l}2013 / 2015 \\
n=18,768\end{array}$ & $\begin{array}{l}2016 / 2017 \\
n=6925\end{array}$ & P-value* \\
\hline Age n (\%) & & & & & & $<0.001$ \\
\hline Birth-17 months & $467(8)$ & $2735(16)$ & $3393(17)$ & $2495(14)$ & $876(13)$ & \\
\hline 18 months -4 years & $1622(26)$ & $5235(31)$ & $5891(30)$ & $4846(27)$ & $1706(26)$ & \\
\hline $5-9$ years & $2137(35)$ & $4625(27)$ & $5282(27)$ & $5379(30)$ & $1840(28)$ & \\
\hline $10-15$ years & $1942(31)$ & $4230(25)$ & $4945(25)$ & $5468(30)$ & $2240(34)$ & \\
\hline Median age (IQR) & $7(4-10)$ & $5(2-10)$ & $5(2-10)$ & $7(2-11)$ & $7(3-12)$ & \\
\hline $\operatorname{Sexn}(\%)$ & & & & & & $<0.001$ \\
\hline Male & $3085(50)$ & $8475(50)$ & $9569(48)$ & $8767(47)$ & $3273(47)$ & \\
\hline Female & $3103(50)$ & $8446(50)$ & $10,192(52)$ & $9976(53)$ & $3641(53)$ & \\
\hline Place of testing $n(\%)$ & & & & & & $<0.001$ \\
\hline Hospital & $3178(51)$ & $8983(53)$ & $9188(47)$ & $7774(41)$ & $2592(37)$ & \\
\hline Health centre & 3002 (49) & $7854(46)$ & $10,477(53)$ & $10,698(57)$ & 4105 (59) & \\
\hline \multicolumn{7}{|l|}{ District type n (\%) } \\
\hline Rural & $394(6)$ & $1981(12)$ & $2849(14)$ & $2807(15)$ & $854(12)$ & $<0.001$ \\
\hline Urban & $5794(94)$ & $14,940(88)$ & $16,912(86)$ & $15,936(85)$ & $6060(88)$ & \\
\hline
\end{tabular}

IQR interquartile range

*Tested using cuzick non-parametric test for trends

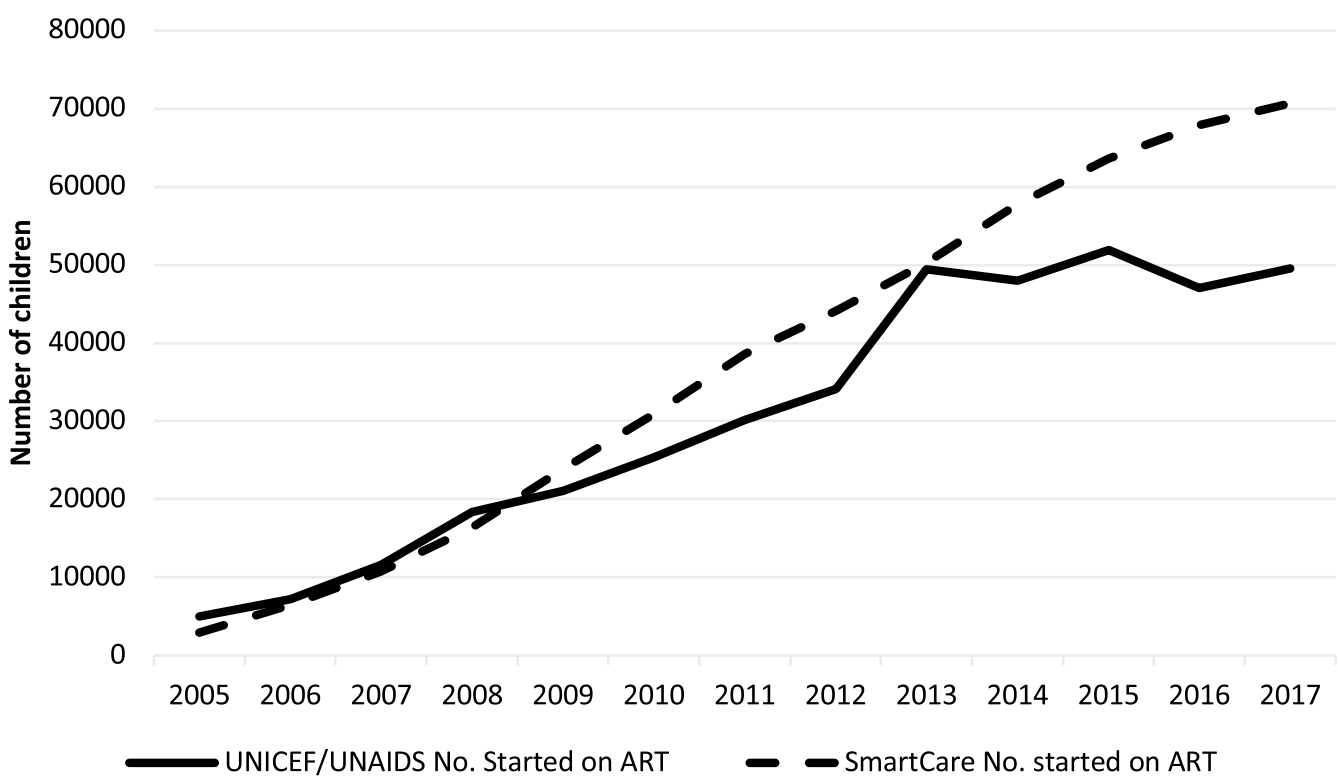

Fig. 3 UNICEF and UNAIDS reported numbers vs SmartCare numbers of children on ART over the years

analysis is required to understand the trends in diagnosis and initiation onto ART.

The incidence of children initiating ART decreased with increasing age, showing the need to promote community-based programs for routine HIV testing in children above 5 years. Facility-based same-day test and treat should also be supported to reduce the drop out of children between HIV diagnosis and ART initiation. The magnitude of missing data may have been small for an epidemiological analysis but is alarming if proper patient follow-up and care is to be achieved. The Ministry of Health needs to ensure data capturing monitoring and reporting are easier for health facilities to complete in order to improve levels of data completeness, accuracy and quality. 
Table 5 Post regression estimates of mean time (in days) between testing HIV positive and ART initiation for children in Zambia between 2004 to 2017

\begin{tabular}{|c|c|c|c|c|}
\hline Characteristic & $\begin{array}{l}\text { Average days to ART initiation } \\
\text { (CI)* crude estimates }\end{array}$ & P-value* & $\begin{array}{l}\text { Average days to ART initiation } \\
\text { (Cl)** adjusted estimates }\end{array}$ & P-value ** \\
\hline \multicolumn{5}{|l|}{ Age } \\
\hline Birth-17 months & $58(40-77)$ & \multirow{4}{*}{$\begin{array}{l}\text { Wald }(3)=2393 \\
P<0.0001\end{array}$} & $116(84-148)$ & \multirow[t]{4}{*}{ Wald $(4)=2412 p<0.0001$} \\
\hline 18 months -4 years & $134(117-151)$ & & $191(160-223)$ & \\
\hline $5-9$ years & $241(224-258)$ & & $299(267-330)$ & \\
\hline $10-15$ years & $262(245-280)$ & & $320(288-352)$ & \\
\hline \multicolumn{5}{|l|}{ Sex } \\
\hline Male & $178(160-196)$ & \multirow{2}{*}{$\begin{array}{l}\text { Wald }(1)=0.10 \\
p>0.05\end{array}$} & $111(85-149)$ & \multirow[t]{2}{*}{ Wald $(5)=2413 p<0.0001$} \\
\hline Female & $179(161-197)$ & & $108(82-147)$ & \\
\hline \multicolumn{5}{|l|}{ Place of testing } \\
\hline Hospital & $175(141-209)$ & \multirow{2}{*}{$\begin{array}{l}\text { Wald }(1)=0.08 \\
P>0.05\end{array}$} & $110(70-149)$ & \multirow[t]{2}{*}{ Wald (5) $=2392 p<0.0001$} \\
\hline Health centre & $181(159-202)$ & & $120(85-155)$ & \\
\hline \multicolumn{5}{|l|}{ District type } \\
\hline Rural & $209(175-242)$ & \multirow{2}{*}{$\begin{array}{l}\text { Wald }(1)=4.35 \\
P<0.05\end{array}$} & $116(84-148)$ & \multirow[t]{2}{*}{ Wald $(4)=2412 p<0.0001$} \\
\hline Urban & $166(145-187)$ & & $30(17-57)$ & \\
\hline
\end{tabular}

Run using multi-level random effects regression clustering at facility level

ICC Intraclass correlation 11\% (IRR $=0.117)$

*Unadjusted model

${ }^{* *}$ Adjusted for age and district of residence

\section{Conclusion}

WHO has spearheaded the fight against HIV and AIDS providing guidelines for both testing and treatment of CLHIV. Zambia has seen substantial increase in proportions of ART initiation among CLHIV and reduction in time to ART initiation which suggests successful implementation of WHO adapted national testing and treatment guidelines and improvements in HIV programming. These efforts and should be supported as they have saved the lives and improved the quality of life of CLHIV in Zambia. However, age related problems with testing suggest that there are critical areas that must be targeted for improvements. These problems might be showing a gap in health system functioning associated with access. There is therefore need to address this and target hard to reach groups if improvements are to be sustained.

\section{Abbreviations}

AIDS: Acquired immunodeficiency syndrome; ANC: Antenatal clinic; ART : Antiretroviral therapy; EFV: Efaviranz; HB: Haemoglobin; HIV: Human immunodeficiency virus; IQR: Interquartile range; LTFU: Lost to follow-up; MTCT: Mother to child transmission; NVP: Nevirapine; PIs: Protease inhibitors; PMTCT: Prevention of mother-to-child transmission; UNAIDS: United Nations programme on HIV/AIDS; UNICEF: United Nations children emergency fund; WHO: World Health Organization.

\section{Acknowledgements}

We would like to thank the Ministry of health in Zambia for granting access to the data that was analysed.

\section{Authors' contributions}

TM, CC and JT participated in the conception of the study co-ordination, acquisition of data and drafted the manuscript. TM and JT carried out the statistical analysis. CM, AK, LL and IC reviewed all the content to validate the data used and the context related to interpretation of the findings. CC and PM participated in the critical review and editing of the manuscript drafts for scientific merit and depth. All authors read and approved the final manuscript.

\section{Funding}

This study was conducted under the SEARCH (Sustainable Evaluation through Analysis of Routinely Collected HIV data) Project supported by the Bill \& Melinda Gates Foundation [OPP1084472].

\section{Availability of data and materials}

The datasets analysed during the current study are not publicly available due the data were collected as routine patient data by the Zambian Ministry of Health who are the owner of the data therefore dataset cannot be shared online. Any further information on the use of dataset should be addressed to the Zambian Ministry of Health through the office of the Permanent Secretary at info@moh.gov.zm. However, for replication and verification of the study, guidance on the dataset and variable names mentioned in the study's methodology section of the manuscript is available from the corresponding author on reasonable request.

\section{Ethics approval and consent to participate}

Ethical approval was obtained from the University of Zambia Biomedical Research Ethical Committee (UNZABREC) under the Sustainable Evaluation and Analysis of Routinely Collected HIV/AIDS data (SEARCH) Project IRB reference number 101-04-16. Ethical approval was also obtained from London school of Hygiene and Tropical Medicine (LSHTM) Research ethics committee approval number 12086 .

\section{Consent for publication}

Not applicable. 


\section{Competing interests}

Authors have no competing interests.

\section{Author details}

${ }^{1}$ School of Public Health, University of Zambia, Lusaka, Zambia. ${ }^{2}$ Ministry of Health, Lusaka, Zambia. ${ }^{3}$ Department of Infectious Disease Epidemiology, Faculty of Epidemiology and Public Health, London School of Hygiene and Tropical Medicine, London, UK. ${ }^{4}$ Department of Population Health, London School of Hygiene and Tropical Medicine, London, UK. ${ }^{5}$ Equip Health, Lusaka, Zambia.

Received: 4 February 2020 Accepted: 5 May 2020

Published online: 14 May 2020

\section{References}

1. UNAIDS. FACT SHEET—WORLD AIDS DAY 2019 GLOBAL HIV STATISTICS. 2019.

2. Avert. HIV and AIDS in Zambia [Internet]. Zambia data. 2019 [cited 2019 Dec 5]. https://www.avert.org/professionals/hiv-around-world/sub-sahar an-africa/zambia.

3. Stringer JS, Zulu I, Levy J, Stringer EM, Mwango A, Chi BH, et al. Rapid scale-up of antiretroviral therapy at primary care sites in Zambia: feasibility and early outcomes. JAMA. 2006;296(7):782-93.

4. Mulenga C. ARV Treatment in Zambia: current issues. [Internet]. Lusaka; 2010. https://slideplayer.com/slide/5958923/.

5. Gilks C VM. Antiretroviral therapy for HIV infection in adults and adolescents: recommendations for a public health approach. 2006.

6. WHO. Antiretroviral therapy of HIV infection in infants and children: towards universal access: recommendations for a public health approach-2010 revision. 2010.

7. WHO. Global update on HIV treatment 2013: results, impact and opportunities. 2013

8. WHO. Consolidated guidelines on the use of antiretroviral drugs for treating and preventing HIV infection: recommendations for a public health approach. 2016

9. C.G. S, C. B-M, J.H. van D, M. C, B. T, Sutcliffe CG, et al. Secular trends in pediatric antiretroviral treatment programs in rural and urban Zambia: a retrospective cohort study. BMC Pediatr [Internet]. 2010;10:no pagination. http://ovidsp.ovid.com/ovidweb.cgi?T=JS\&PAGE=refer ence $\& D=$ med6\&NEWS $=N \& A N=20673355 \% 5$ Cnhttp://www.biome dcentral.com/1471-2431/10/54\%5Cnhttp://ovidsp.ovid.com/ovidw eb.cgi?T $=J S \& P A G E=$ reference $\& D=$ emed $12 \& N E W S=N \& A N=51018853$.

10. Kankasa C, Carter RJ, Briggs N, Bulterys M, Chama E, Cooper ER, et al. Routine offering of HIV testing to hospitalized pediatric patients at University Teaching Hospital Lusaka, Zambia: acceptability and feasibility. J Acquir Immune Defic Syndr. 2009;51(2):202-8.

11. Adedimeji A, Edmonds A, Hoover D, Shi Q, Sinayobye JD, Nduwimana $M$, et al. Characteristics of HIV-infected children at enrollment into care and at antiretroviral therapy initiation in Central Africa. PLoS ONE. 2017;12(1):e0169871.

12. Sutcliffe CG, Bolton-Moore C, van Dijk JH, Cotham M, Tambatamba BMW. Secular trends in pediatric antiretroviral treatment programs in rural and urban Zambia: a retrospective cohort study. BMC Pediatr. 2010;20(1):54.

13. Sando D, Spiegelman D, Machumi L, Mwanyika-Sando M, Aris E, Muya A, et al. Time trends of baseline demographics and clinical characteristics of HIV infected children enrolled in care and treatment service in Dar es Salaam, Tanzania. BMC Infect Dis. 2015;15(1):157.

14. Davies MA, Phiri S, Wood R, Wellington M, Cox V, Bolton-Moore C, et al. Temporal trends in the characteristics of children at antiretroviral therapy initiation in Southern Africa: The leDEA-SA Collaboration. PLOS ONE. 2013;8(12):e81037.

15. $\mathrm{MOH}$. National HIV And AIDS Strategic Framework 2017-2021. Lusaka; 2016.

16. Bolton-Moore C, Mubiana-Mbewe M, Cantrell RA, Chintu N, Stringer EM, Chi BH, Sinkala M, Kankasa C, Wilson CM, Wilfert CM, Mwango A, Jens L,
EJ. Abrams, M Bulterys, Jeffrey S.A, Stringer M. Clinical outcomes and CD4 cell response in children receiving antiretroviral therapy at primary health care facilities in Zambia. JAMA. 2007;298(16):1888-99.

17. $\mathrm{MOH}$. The list of Health Facilities in Zambia, Preliminary report (draft No. 15). 2012.

18. $\mathrm{MOH}$. The 2017 List of Health Facilities in Zambia. Lusaka; 2017.

19. $\mathrm{MOH}$. The 2012 List of Health Facilities in Zambia (Version No. 15). Lusaka; 2013.

20. Sutcliffe CG, Bolton-Moore C, van Dijk JH, Cotham M, Tambatamba BMW. Secular trends in pediatric antiretroviral treatment programs in rural and urban Zambia: a retrospective cohort. BMC Pediatr. 2010;10:54.

21. $\mathrm{MOH}$. Zambia Consolidated Guidelines for Prevention and Treatment of HIV Infection. Ministry of Health. Lusak; 2018.

22. UNICEF. Children and AIDS: Fourth Stocktaking Report, 2009. 2009.

23. UNICEF. For every child, end AIDS-seventh stocktaking report. New york; 2016.

24. UNICEF. Children and AIDS. A stocktaking report. Actions and progress during the first year of Unite for Children, Unite against AIDS. Geneva; 2007.

25. UNICEF. Towards an AIDS-free generation: children and AIDS: sixth stocktaking report. 2013

26. UNICEF. Children and AIDS: Third Stocktaking Report, 2008-Summary. 2008.

27. UNAIDS. Report on the global AIDS epidemic: 4th global report: 2004

28. UNAIDS. Global Report 2012: UNAIDS Report on the Global AIDS Epidemic. 2012.

29. UNAIDS. 2008 report on the global AIDS epidemic. 2008.

30. UNAIDS. Zambia country profile. Geneva, Switzerland; 2014.

31. UNAIDS. Global AIDS update 2016. 2016.

32. UNAIDS. UNAIDS DATA 2017. 2017.

33. UNAIDS. feature story :Test and treat showing results in Uganda and Zambia [Internet]. 2018 [cited 2018 Jul 6]. http://www.unaids.org/en/resou rces/presscentre/featurestories/2018/April/test-and-treat-showing-resul ts-in-uganda-and-zambia2018.

34. Ghosh S, Pahwa P. Assessing bias associted with missing data from joint Canada/USA survey of health: an application. JSM Biometrics. 2008

35. Avert. HIV and AIDS in Zambia| AVERT [Internet]. 2017 [cited 2017 Jul 5]. https://www.avert.org/professionals/hiv-around-world/sub-saharan-afric a/zambia.

36. Mokgatle MM, Madiba S. The burden of disease on HIV-infected orphaned and non-orphaned children accessing primary health facilities in a rural district with poor resources in South Africa: a cross-sectional survey of primary caregivers of HIV-infected children aged 5-18 years. Infect Dis Poverty. 2015;4(11):18.

37. Ferrand RA, Bandason T, Musvaire P, Larke N, Nathoo K, Mujuru H, et al. Causes of acute hospitalization in adolescence: burden and spectrum of HIV-related morbidity in a country with an early-onset and severe HIV epidemic: a prospective survey. PLoS Med. 2010;7(2):e1000178.

38. Bandason T, Langhaug LF, Makamba M, Laver S, Hatzold K, Mahere S, et al. Burden of HIV among primary school children and feasibility of primary school-linked HIV testing in Harare, Zimbabwe: a mixed methods study. AIDS Care. 2013;25(12):1520-6. https://doi.org/10.1080/09540 121.2013 .780120

39. Ferrand RA, Corbett EL, Wood R, Hargrove J, Ndhlovu CE, Cowan FM, et al. AIDS among older children and adolescents in Southern Africa: projecting the time course and magnitude of the epidemic. AIDS. 2009;23(15):2039-46.

40. Bwana VM, Frimpong C, Simulundu E, Mfinanga SG, Mboera LEG, Michelo C. Accessibility of services for early infant diagnosis of human immunodeficiency virus in Sub-Saharan Africa: a systematic review. Tanzan J Health Res. 2016;18(3):1-18.

\section{Publisher's Note}

Springer Nature remains neutral with regard to jurisdictional claims in published maps and institutional affiliations. 